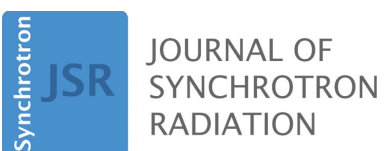

ISSN 1600-5775

Received 17 July 2017

Accepted 17 July 2017

Keywords: in situ; correction; X-ray; mirror.

\section{In situ beamline analysis and correction of active optics. Erratum}

John Sutter, ${ }^{*}$ Simon Alcock and Kawal Sawhney

Diamond Light Source Ltd, Harwell Science and Innovation Campus, Chilton, Didcot,

Oxfordshire OX11 0DE, UK. *Correspondence e-mail: john.sutter@diamond.ac.uk

A correction to one of the equations in the paper by Sutter et al. (2012). [J. Synchrotron Rad. 19, 960-968] is made.

Equation (5) in the paper by Sutter et al. (2012) should be

$$
B(x)=\frac{\left(C_{1}+C_{2}\right) x}{2 E I}+\frac{\left(C_{1}-C_{2}\right) x^{2}}{2 L E I} .
$$

Note the additional factor of 2 in the denominator of the quadratic term on the right-hand side.

\section{References}

Sutter, J., Alcock, S. \& Sawhney, K. (2012). J. Synchrotron Rad. 19, 960-968.

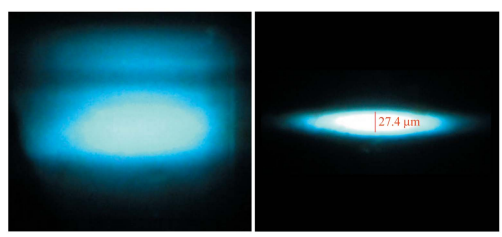

(C) 2017 International Union of Crystallography 